\title{
Visual Disorders Outcome after Endoscopic Endonasal Trans-Sphenoidal Surgery of Pituitary Macroadenomas
}

\author{
Wissame El Bakkouri ${ }^{*}$, Picard Hervé2, Brice Dzidzinyo ${ }^{3}$, Abdellaoui Anis1, \\ Boyeldieu Louise1, Corré Alain1, Vignal Catherine', Boucenna Malika ${ }^{4}$, Ayache Denis ${ }^{1}$ \\ ${ }^{1}$ ENT Department, Fondation Ophtalmologique Adolphe de Rothschild, Paris, France \\ ${ }^{2}$ Clinical Research Unit, Fondation Ophtalmologique Adolphe de Rothschild, Paris, France \\ ${ }^{3} \mathrm{OPH}$ Department, Fondation Ophtalmologique Adolphe de Rothschild, Paris, France \\ ${ }^{4}$ Radiological Department, Fondation Ophtalmologique Adolphe de Rothschild, Paris, France \\ Email: *welbakkouri@fo-rothschild.fr
}

Received 21 March 2016; accepted 14 May 2016; published 17 May 2016

Copyright (C) 2016 by authors and Scientific Research Publishing Inc.

This work is licensed under the Creative Commons Attribution International License (CC BY). http://creativecommons.org/licenses/by/4.0/

(c) (i) Open Access

\begin{abstract}
Objective: Describe the outcome of visual disorders after endonasal transsphenoidal (EET) surgery of pituitary macroadenomas with preoperative chiasmal compression. Patients and Methods: From 2009 to 2013, 225 patients underwent EET surgery for sellar tumor. Among them, 168 suffered from visual disorders induced by chiasmatic compression, of which 88 met the inclusion criteria for this study. Average duration of follow up was $1.8 \mathrm{yrs} \pm 0.4 \mathrm{yrs}$. All patients had sellar MRI before surgery and yearly postoperatively, visual acuity (VA) and/or visual field (VF) measurements before, 3 months after surgery and yearly postoperatively. Results: All tumors were macroadenomas with a mean preoperative MRI-estimated volume of 10.0 \{plus minus\} $9.07 \mathrm{~cm}^{3}$. Preoperative VA was impaired with an average of $0.43 \pm 0.13 \operatorname{LogMAR}$ (left eye) and $0.36 \pm 0.14$ LogMAR (right eye) and VF was disturbed in $99 \% \pm 2 \%$ of the cases with the most frequent disorder being bitemporal hemianopsia (38 patients). Post-operatively, the mean residual MRI-estimated tumor volume was $3.15 \pm 3.71 \mathrm{~cm}^{3}$. Mean tumor volume reduction was $62 \% \pm 9 \%(p<$ $0.001)$. Optic chiasmal compression resolved in $72 \% \pm 10 \%$ of the cases. Visual function improved in $86 \% \pm 7 \%$ of cases ( $p<0.001$ ). Conclusion: Endoscopic endonasal management of pituitary gland neoplasms is effective to reduce tumor volume. This technique achieved significant visual improvement in the majority of cases presenting with chiasmal compression syndrome.
\end{abstract}

\section{Keywords}

Pituitary, Macroadenoma, Visual Disorder, Chiasm Compression, Endoscopy, Transsphenoidal

\footnotetext{
${ }^{*}$ Corresponding author.

How to cite this paper: El Bakkouri, W., Hervé, P., Dzidzinyo, B., Anis, A., Louise, B., Alain, C., Catherine, V., Malika, B. and Denis, A. (2016) Visual Disorders Outcome after Endoscopic Endonasal Trans-Sphenoidal Surgery of Pituitary Macroadenomas. International Journal of Otolaryngology and Head \& Neck Surgery, 5, 134-140.

http://dx.doi.org/10.4236/ijohns.2016.53023
} 


\section{Introduction}

Pituitary adenomas accounts for about $10 \%$ of intracranial tumors among which $14 \%$ to $28 \%$ are non-functioning adenomas [1]-[3]. Such cases spontaneously grow up yielding to typical visual disorders related to optic chiasmal compression. Nowadays, the incidence of optic chiasmal compression is observed with MRI in $9 \%$ of the pituitary macroadenomas [4]. More rarely, involvement of the cavernous sinus leads to oculomotor symptoms. Such complications justify surgery to avoid visual degradation and to stop tumor growth progression. Endoscopic endonasal transsphenoidal (EET) surgery proved to be an effective procedure for such cases [2] [5] [6].

The aim of this retrospective study was to analyze visual outcome after EET surgery for pituitary macroadenomas.

\section{Patients and Methods}

From 2009 to 2013, 225 patients underwent surgical resection of pituitary tumors via endoscopic endonasal trans-sphenoidal approach. From this cohort, we retrospectively collected cases with visual impairment due to optic chiasmal compression by pituitary macroadenoma. Inclusion criteria were: 1) preoperative visual impairment (defined by visual loss and/or campimetric deficit and/or other symptoms like a diplopia); 2) pre and post operative MRI and visual status available; 3) histologically proven pituitary adenoma; 4) minimum of 3 months follow-up after surgery. Among 225 patients, 168 presented visual impairment from chiasm compression, and 88 cases met criteria for inclusion.

39 patients were females and 49 males (sex ratio 1.26). Mean age at surgery was $54.53 \pm 3.01$ years. All tumors were macroadenomas $(\mathrm{n}=76$; diameter $\geq 10 \mathrm{~mm})$ or giant adenomas $(\mathrm{n}=12$; diameter $\geq 40 \mathrm{~mm})$. The majority of tumors were gonadotropic ( $n=72$ patients). Baseline characteristics are summarized in Table 1 .

All the patients had a preoperative MRI evaluation of the size of the pituitary adenoma and a CT scan to preoperatively study nasal fossa, sinus and skull base anatomy and for surgical navigation guidance. Tumor volume has been approximated based on MRI measurements, using an ellipsoid model (volume $=4 / 3 \times \pi \times 1 / 2 \mathrm{~d}_{1}$ $\times 1 / 2 d_{2} \times 1 / 2 d_{3}$ ) where $d_{1}, d_{2}$ and $d_{3}$ are the maximum tumor diameter in the orthogonal spatial axes [7].

All the patients had a visual evaluation including measurement of visual acuity (VA) and/or visual field (VF)

\begin{tabular}{ccc} 
Table 1. Pre operative patients characteristics. & \\
\hline & Men & Number of patients (n) \\
\hline Sex & Women & 49 \\
\hline Mean age & 54.53 yrs \pm 3.01 yrs & \\
\hline & Gonadotrophic & 72 \\
Histological type of the tumor & Prolactinoma & 4 \\
& Corticotrophic & 7 \\
& Multi & 3 \\
& Somatotrophic & 1 \\
\hline Extrasellar extension & Thyreotrophic & 1 \\
\hline & Suprasellar component & 77 Yes/8 No \\
& Laterosellar component & 5 Yes/80 No \\
& Inferior extension & 14 Yes/71 No \\
\hline Radiotherapy or radiosurgery & Acute (pituitary apoplexy) & 4 \\
\hline Onset of the visual acuity impairment & Rapid & 28 \\
& Progressive & 41 \\
\hline & One & 88 \\
\hline & Two & 14 \\
\hline & More than two & 1 \\
\hline
\end{tabular}


by Goldman or Humphrey perimeter. VA impairment was expressed in LogMAR (LogMAR 0 corresponding to a perfect vision and LogMAR 2.3 to a very low vision).

All the patients underwent EET removal of the tumor with neuronavigation guidance. The surgery was carried out by a team comprising a neurosurgeon and an ENT surgeon, both experienced in "four hands" EE surgery. The surgical goals were to achieve maximum decompression of the optic chiasm, to remove as much as possible of the tumoral volume and to provide tissue for histological analysis.

Two major criteria were assessed: diminution of the MRI-estimated tumor volume, and visual outcome measured by VA and/or VF at the last follow-up visit.

The mean postoperative follow up was of $1.8 \pm 0.4$ years.

\section{Statistical Analysis}

Data were retrieved from the patient's hospital files, encoded in a Microsoft Excel spreadsheet and analyzed using the R statistical package. Means were compared before/after surgery using paired Student's test and proportions were compared using Mc Nemar test with Yates correction, with alpha 5\%. Confidence intervals are 95\%.

\section{Results}

\subsection{Tumor Volume}

Preoperative tumor volume was $10.0 \pm 9.07 \mathrm{~cm}^{3}$. Postoperatively, the mean residual MRI-estimated tumor volume was $3.15 \pm 3.71 \mathrm{~mm} 3(\mathrm{p}<0.001)$.

Reduction of the tumor was superior to $70 \%$ of its initial volume in $50 \%$ of the cases $(n=44)$; resection was near-complete (more than $90 \%$ reduction of the tumoral volume) in $23.8 \%$ of the cases $(n=21)$ (Figure 1 and Figure 2).

\subsection{Visual Function}

Prior to surgery, $4.5 \%$ of the patients $(n=4)$ presented a pituitary apoplexy and were not tested because of the surgical emergency of the case. Among the whole cohort, $6.8 \%$ of the patients $(n=6)$ had diplopia despite no visual defect or VF abnormality.

The mean preoperative VA impairment was $0.43 \pm 0.13 \operatorname{LogMAR}$ for the left eye and $0.36 \pm 0.14 \operatorname{LogMAR}$

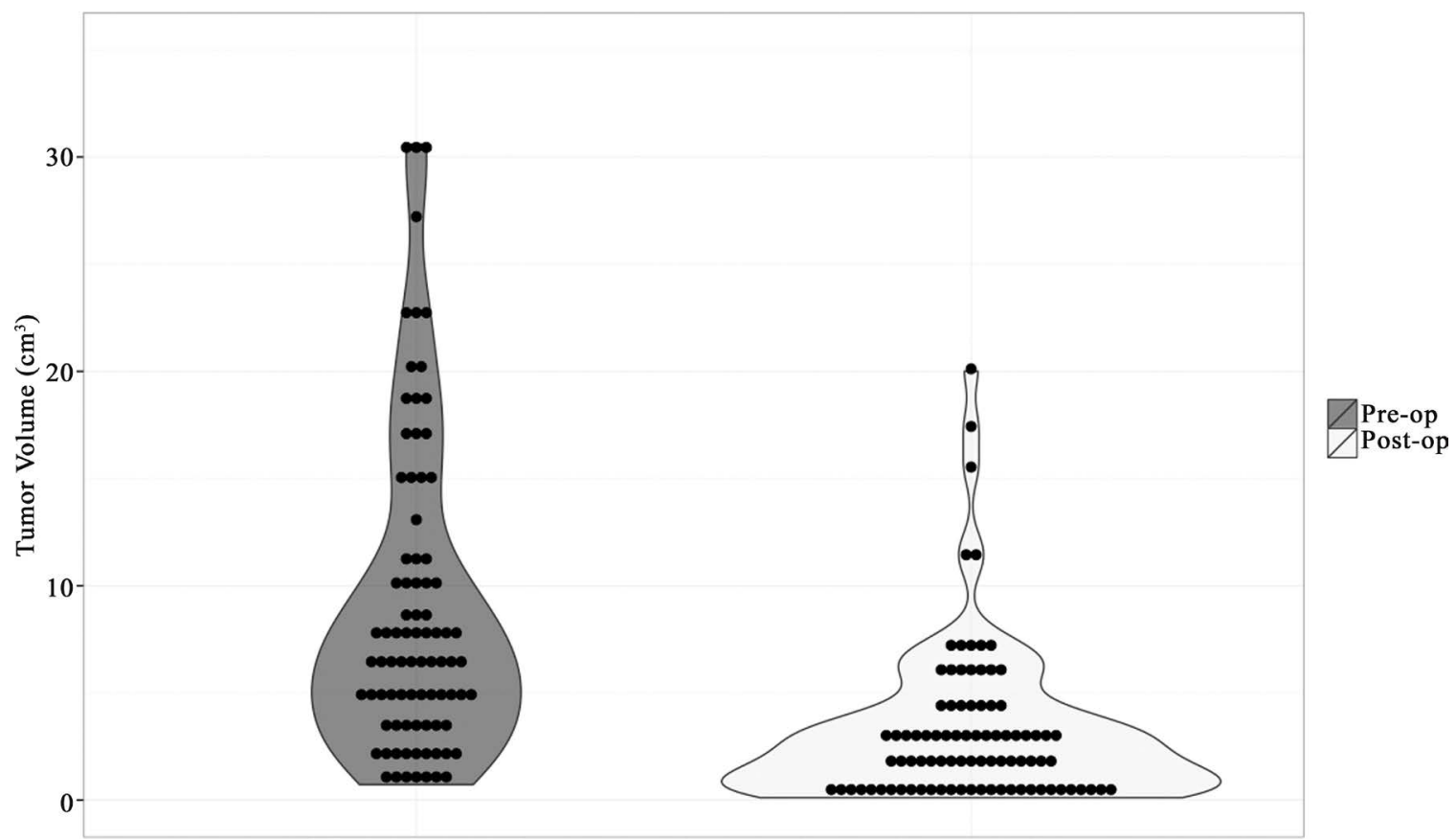

Figure 1. Reduction of the tumor volume after surgical intervention. 


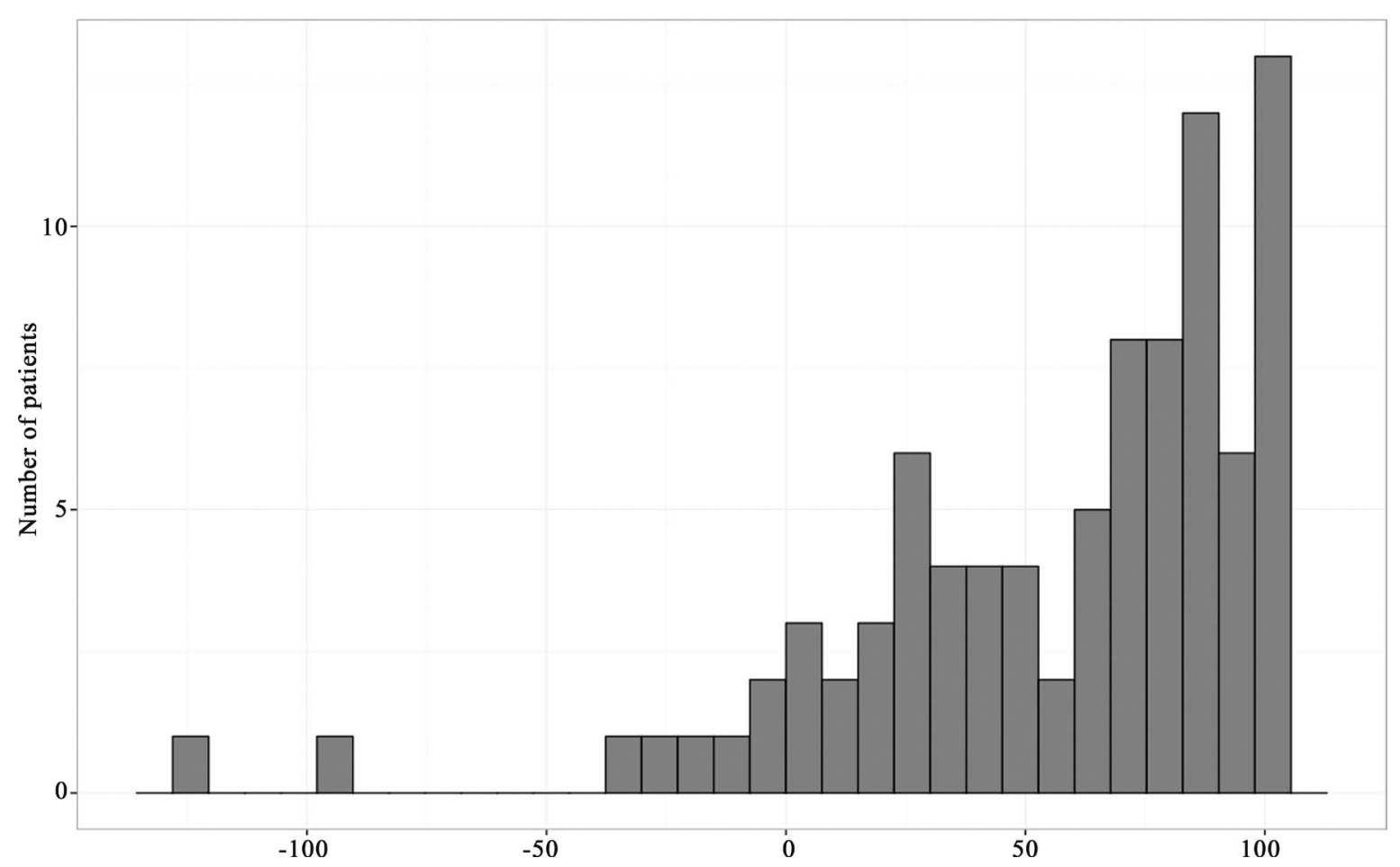

Figure 2. \% rediction of tumor volume after surgery.

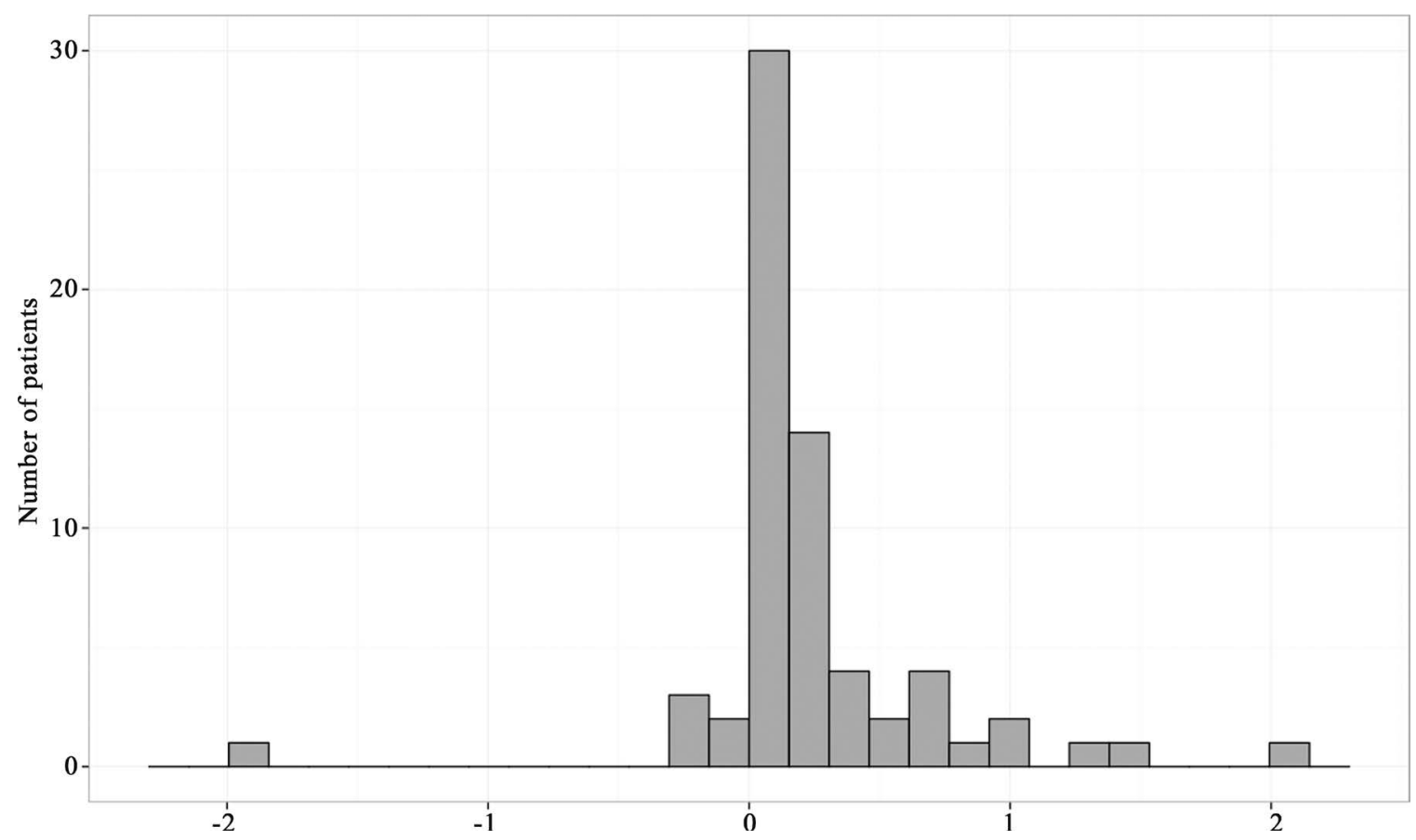

Figure 3. Visual acuity gain (LogMAR) after surgery for the left eye (mean gain was $0.24 \pm 0.13 \operatorname{LogMAR}$ ).

for the right eye.

The mean postoperative VA impairment was of $0.16 \pm 0.1 \operatorname{LogMAR}$ for the left eye and of $0.16 \pm 0.11$ LogMAR for the right eye (Figure 3 and Figure 4). Mean VA impairment after surgery was $0.24 \pm 0.13$ LogMAR for the left eye and $0.24 \pm 0.12 \operatorname{LogMAR}$ for the right eye. The difference before/after surgery was significant $(\mathrm{p}<0.01)$. 
If comparing pre and postoperative VA, data were available for 63 patients. There was a clinically significant improvement of the VA (average VA of both eyes improving by 0.2 LogMAR or more) in $47 \%$ of the cases ( $\mathrm{n}=$ 30/63).

Preoperatively, 81 patients had a VF evaluation among whom $46.9 \%(n=38)$ had a bitemporal hemianopsia and $1.2 \%(n=1)$ had no VF cut (Table 2$)$.

Assessment of VF 3 months after surgery was performed in 78 patients. It showed complete recovery in 15 cases, partial recovery in 27 cases and no improvement in 36 cases (Table 3 ).

\section{Discussion}

EET surgery is a widely accepted procedure for the resection of micro, macro and giant pituitary adenoma [1] [5] [8]-[10]. It allows total resection in almost $20 \%$ of the cases in macroadenomas and giant adenom Apr;

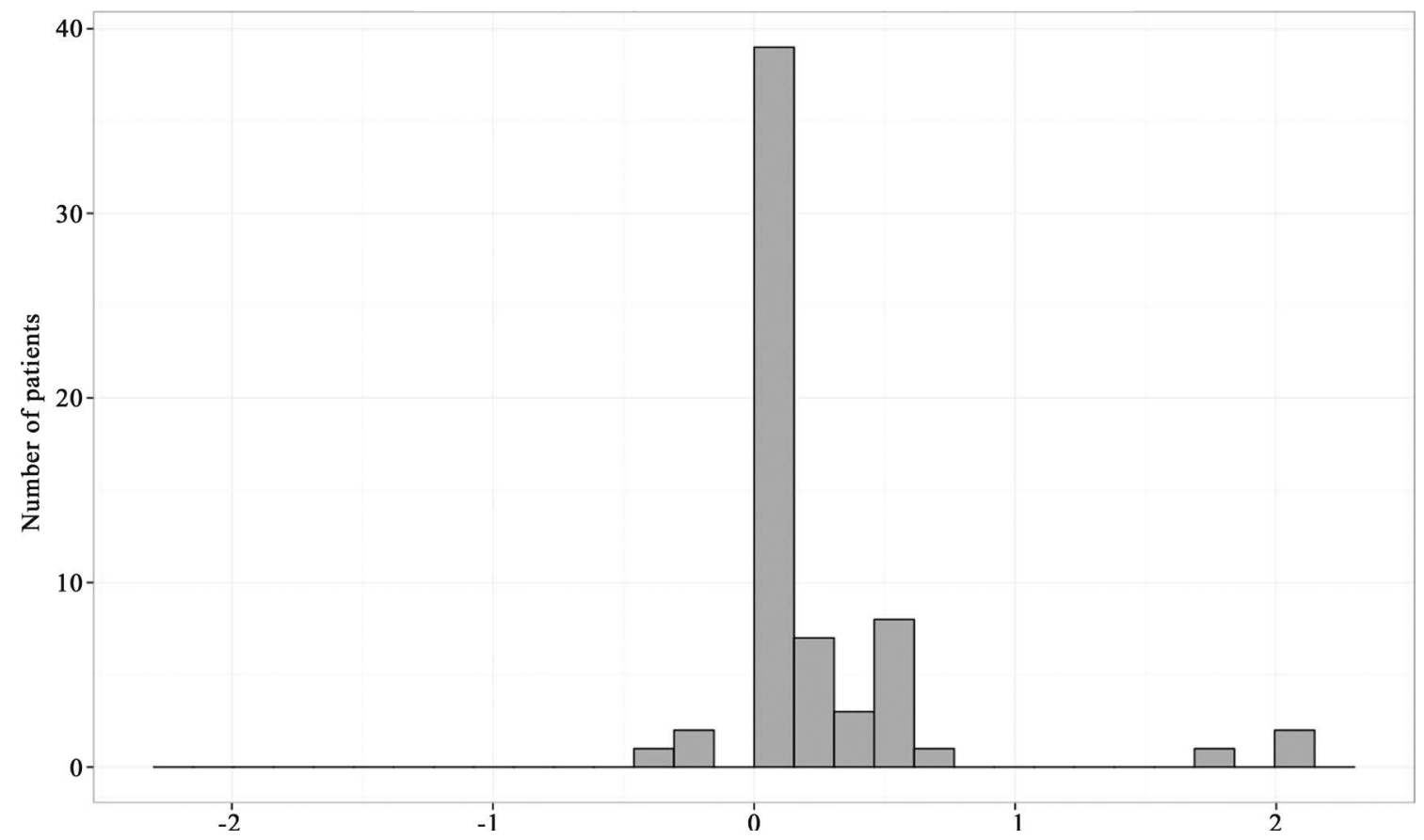

Figure 4. Visual acuity gain (LogMAR) after surgery for the right eye (mean gain was $0.24 \pm 0.12 \operatorname{LogMAR}$ ).

Table 2. Pre operative visual field (VF) abnormalities.

\begin{tabular}{ccc}
\hline VF impairment & Frequence & Number of patients \\
\hline Bitemporal hemianopsia & $46.9 \%$ & 38 \\
Lateral homonymous hemianopsia & $4.9 \%$ & 4 \\
Other VF cut & $30.9 \%$ & 25 \\
Unilateral hemianopsia & $16 \%$ & 13 \\
No VF abnormality & $1.2 \%$ & 1 \\
TOTAL & $100 \%$ & 81 \\
\hline
\end{tabular}

Table 3. Post operative visual field abnormalities.

\begin{tabular}{ccc}
\hline VF impairment & Frequence & Number of patients \\
\hline Bitemporal hemianopsia & $20.5 \%$ & 16 \\
Lateral homonymous hemianopsia & $3.8 \%$ & 3 \\
Other VF cut & $52.6 \%$ & 41 \\
Unilateral hemianopsia & $3.8 \%$ & 3 \\
No VF abnormality & $19.2 \%$ & 15 \\
TOTAL & $100 \%$ & 78 \\
\hline
\end{tabular}


158(4): $677-683$ as [2] [11]. Other series conclude to total resection achieved in $38 \%$ to $66 \%$ of the cases, even for giant adenomas involving the cavernous sinus [1] [3] [12]-[14]. Such encouraging results are explained by an improved panoramic visualization with EET, particularly for structures like the optic-carotid recess and the diaphragm sella. In case of visual impairment, EET is also indicated and yields good results [3]. In our article, reduction of the tumor was superior to $70 \%$ of its initial volume in $50 \%$ of the cases. There was a clinically significant improvement of the VA in $47 \%$ of the cases $(n=30 / 63)$. We observed $17 \%$ of complete recovery of the VA and $19.23 \%$ of complete recovery of the VF $(n=15 / 78)$.

\subsection{Visual Tests}

Between 2009 and 2013, 225 patients underwent EET resection of a sellar tumor at our institution. Among them $168(74.6 \%)$ presented visual disorders, in agreement with results reported in the literature with rates ranging from $31 \%$ to $89 \%$ [1] [4] [6] [15]-[17]. In our series, 88 patients met inclusion criteria. Other patients were not eligible for various reasons (early lost of follow-up, unavailable MRI or visual examination data, other histological type of tumor).

The functional results were better for VF (total recovery in 19.2\% of the cases and partial recovery in $35 \%$ ) than for VA (total recovery in 17\% and improvement in 30\% of the cases). This was noted in a series of juraska et al. [2]. On the other hand, Peter et al. [4] found better outcomes concerning VF than VA.

Cohen et al. [18] found an inverse correlation between the duration of visual symptoms and final outcome for both VF and VA.

\subsection{MRI}

In the literature, many authors recommended calculating tumor volume rather than diameters because it is a significant predictor of imaging outcome on long-term follow-up [13]. Hoffstetter et al. suggested a volume of $\geq 10$ $\mathrm{cm}^{3}$ as a modern definition of pituitary macroadenomas [19]. However, as noted by Egger et al. simple methods as geometric models like the ellipsoidal model provide a rough approximation of the tumor volume [7].

In our retrospective study, tumor volume was estimated using an ellipsoid model. We believe that with this model, volumes may be underestimated but the results were consistent with those found in the literature [20]. For Juraska et al. [2], volumetric analysis provides a more accurate measurement of the extent of the resection than ellipsoidal volume calculation. In our series, we approximated the tumoral volume by calculating ellipsoidal volumes because native MRI was not always at the radiologist disposal to calculate volume using dedicated software.

Postoperatively, the residual tumor volume was $3.15 \pm 3.71 \mathrm{~cm}^{3}(\mathrm{p}<0.01)$. As might be expected, the rate of residual tumor is higher in macro-adenoma (and giant adenoma), particularly in suprasellar and cavernous sinus spreading [2] [13]. Juraska et al. reported complete resection in $24.2 \%$ in their series of 76 giant and large macro-adenomas [2]. In our series, $23.8 \%$ of the patients had total or near total resection.

\subsection{Limits of the Study}

This is a retrospective study so we couldn't study the medical chart of the 225 operated on between 2009 and 2013 because of insufficient data. We decided to focus on pituitary adenomas excluding all other histological type of pituitary tumors because we don't know the evolution of all types of tumors.

\section{Conclusion}

Visual disorders are common complications of pituitary adenoma natural growth. In this series, we found that endoscopic endonasal transsphenoidal resection of macroadenoma with chiasm compression syndrome was reliable in improving visual impairment.

\section{Conflict of Interest}

The authors have no personal financial or institutional interest in any of the drugs, materials or devices described in this article. 


\section{References}

[1] Torales, J., Halperin, I., Hanzu, F., Mora, M., Alobid, I., De Notaris, M., et al. (2014) Endoscopic Endonasal Surgery for Pituitary Tumors. Results in a Series of 121 Patients Operated at the Same Center and by the Same Neurosurgeon. Endocrinología y Nutrición (English Edition), 61, 410-416. http://dx.doi.org/10.1016/j.endoen.2014.07.002

[2] Juraschka, K., Khan, O.H., Godoy, B.L., Monsalves, E., Kilian, A., Krischek, B., et al. (2014) Endoscopic Endonasal Transsphenoidal Approach to Large and Giant Pituitary Adenomas: Institutional Experience and Predictors of Extent of Resection. Journal of Neurosurgery, 121, 75-83. http://dx.doi.org/10.3171/2014.3.JNS131679

[3] Gómez, R.C. (2014) Non-Functioning Pituitary Tumors: 2012 Update. Endocrinología y Nutrición (English Edition), 61, 160-170. http://dx.doi.org/10.1016/j.endoen.2014.02.011

[4] Peter, M. and De Tribolet, N. (1995) Visual Outcome after Transsphenoidal Surgery for Pituitary Adenomas. British Journal of Neurosurgery, 9, 151-157. http://dx.doi.org/10.1080/02688699550041485

[5] Ammirati, M., Wei, L. and Ciric, I. (2013) Short-Term Outcome of Endoscopic versus Microscopic Pituitary Adenoma Surgery: A Systematic Review and Meta-Analysis. Journal of Neurology, Neurosurgery \& Psychiatry, 84, 843-849. http://dx.doi.org/10.1136/jnnp-2012-303194

[6] Chone, C.T., Sampaio, M.H., Sakano, E., Paschoal, J.R., Garnes, H.M., Queiroz, L., et al. (2014) Endoscopic Endonasal Transsphenoidal resection of pituitary Adenomas: Preliminary Evaluation of Consecutive Cases. Brazilian Journal of Otorhinolaryngology, 80, 146-151. http://dx.doi.org/10.5935/1808-8694.20140030

[7] Davies, B.M., Carr, E., Soh, C. and Gnanalingham, K.K. (2016) Assessing Size of Pituitary Adenomas: A Comparison of Qualitative and Quantitative Methods on MR. Acta Neurochirurgica (Wien), 158, 677-683.

[8] Cusimano, M.D., Kan, P., Nassiri, F., Anderson, J., Goguen, J., Vanek, I., et al. (2012) Outcomes of Surgically Treated Giant Pituitary Tumours. Canadian Journal of Neurological Sciences, 39, 446-457. http://dx.doi.org/10.1017/S0317167100013950

[9] Koutourousiou, M., Gardner, P.A., Fernandez-Miranda, J.C., Paluzzi, A., Wang, E.W. and Snyderman, C.H. (2013) Endoscopic Endonasal Surgery for Giant Pituitary Adenomas: Advantages and Limitations. Journal of Neurosurgery, 118, 621-631. http://dx.doi.org/10.3171/2012.11.JNS121190

[10] Yang, I., Wang, M.B. and Bergsneider, M. (2010) Making the Transition from Microsurgery to Endoscopic TransSphenoidal Pituitary Neurosurgery. Neurosurgery Clinics of North America, 21, 643-651.

[11] Komotar, R.J., Starke, R.M., Raper, D.M.S., Anand, V.K. and Schwartz, T.H. (2012) Endoscopic Endonasal Compared with Microscopic Transsphenoidal and Open Transcranial Resection of Giant Pituitary Adenomas. Pituitary, 15, 150 159. http://dx.doi.org/10.1007/s11102-011-0359-3

[12] Roelfsema, F., Biermasz, N.R. and Pereira, A.M. (2012) Clinical Factors Involved in the Recurrence of Pituitary Adenomas after Surgical Remission: A Structured Review and Meta-Analysis. Pituitary, 15, 71-83. http://dx.doi.org/10.1007/s11102-011-0347-7

[13] Gopalan, R., Schlesinger, D., Vance, M.L., Laws, E. and Sheehan, J. (2011) Long-Term Outcomes after Gamma Knife Radiosurgery for Patients with a Nonfunctioning Pituitary Adenoma. Neurosurgery, 69, 284-293. http://dx.doi.org/10.1227/NEU.0b013e31821bc44e

[14] Berkmann, S., Schlaffer, S., Nimsky, C., Fahlbusch, R. and Buchfelder, M. (2014) Follow-Up and Long-Term Outcome of Nonfunctioning Pituitary Adenoma Operated by Transsphenoidal Surgery with Intraoperative High-Field Magnetic Resonance Imaging. Acta Neurochirurgica (Wien), 156, 2233-2243. http://dx.doi.org/10.1007/s00701-014-2210-x

[15] Paluzzi, A., Fernandez-Miranda, J.C., Tonya Stefko, S., Challinor, S., Snyderman, C.H. and Gardner, P.A. (2014) Endoscopic Endonasal Approach for Pituitary Adenomas: A Series of 555 Patients. Pituitary, 17, 307-319. http://dx.doi.org/10.1007/s11102-013-0502-4

[16] Robenshtok, E., Benbassat, C.A., Hirsch, D., Tzvetov, G., Cohen, Z.R., Iraqi, H.M., et al. (2014) Clinical Course and Outcome of Nonfunctioning Pituitary Adenomas in the Elderly Compared with Younger Age Groups. Endocrine Practice, 20, 159-164.

[17] Murad-Kejbou, S. and Eggenberger, E. (2009) Pituitary Apoplexy: Evaluation, Management, and Prognosis. Current Opinion in Ophthalmology, 20, 456-461. http://dx.doi.org/10.1097/ICU.0b013e3283319061

[18] Cohen, A.R., Cooper, P.R., Kupersmith, M.J., Flamm, E.S. and Ransohoff, J. (1985) Visual Recovery after Transsphenoidal Removal of Pituitary Adenomas. Neurosurgery, 17, 446-452. http://dx.doi.org/10.1227/00006123-198509000-00008

[19] Hofstetter, C.P., Nanaszko, M.J., Mubita, L.L., Tsiouris, J., Anand, V.K. and Schwartz, T.H. (2012) Volumetric Classification of Pituitary Macroadenomas Predicts Outcome and Morbidity Following Endoscopic Endonasal Transsphenoidal Surgery. Pituitary, 15, 450-463. http://dx.doi.org/10.1007/s11102-011-0350-z

[20] Egger, J., Kapur, T., Nimsky, C. and Kikinis, R. (2012) Pituitary Adenoma Volumetry with 3D Slicer. PloS One, 7, e51788. http://dx.doi.org/10.1371/journal.pone.0051788 